\title{
The Capitalization of Personal Self-Efficacy: Yields for Practices and Research Development
}

\author{
Huy P. Phan ${ }^{1}$ \\ ${ }^{1}$ School of Education, University of New England, Armidale, Australia \\ Correspondence: Huy P. Phan, School of Education, University of New England, Armidale, Australia. Tel: \\ 61-2-6773-3327.E-mail: hphan2@une.edu.au
}

Received: December 15, 2012

Accepted: January 8, 2013 Online Published: March 20, 2013

doi:10.5539/jedp.v3n1p72

URL: http://dx.doi.org/10.5539/jedp.v3n1p72

\begin{abstract}
Quality learning in achievement contexts is an important feat for enhancement and development. In a similar vein, in the contexts of secondary schooling, academic engagement is a major element for scholarly consideration (e.g., "I really enjoy coming to school, and taking part in these social activities"). In the area of educational psychology, there have been various cognitive (e.g., achievement goal orientations) and noncognitive (e.g., self-concept) theories that note and explain individuals' learning, academic engagement, motives, etc. Bandura's (1986) social cognitive theory, especially the tenets of personal self-efficacy (Bandura, 1977, 1997) have been researched and used to account and predict individuals' cognition and behaviors in educational and non-educational settings.

This theoretical review then, explores a few identified issues related to quality learning - for example, one's sense of identity and how this psychosocial facet features in the teaching and learning processes. We also scope, in the latter section of this article, the potency of personal self-efficacy in the contexts of quality learning and school engagement, and how this theoretical orientation, in totality, may result in effective practices and continuing research development.
\end{abstract}

Keywords: sense of identity, quality learning, social cognitive theory, personal self-efficacy

\section{Introduction}

It is not surprising that disadvantaged groups in societies are below standard in learning and achievement outcomes. There is recognition, in particular, that disadvantaged youths engage in maladaptive behaviors, such as school disengagement, partaking in criminal activities (e.g., petty crime), and antisocial actions. The quest then, for us as educators, is to consider appropriate measures that could promote and encourage positive and prosocial behaviors in both educational and non-educational settings. Our examination of the empirical literature suggests there are a number of theoretical orientations, which may assist and facilitate positive learning experiences and quality outcomes. Social cognitive theory (Bandura, 1977b, 1986), encompassing the tenet of personal self-efficacy (Bandura, 1977a, 1997) is of significance, enabling us to explain individuals' emotions, cognition and behaviors. There is substantial research (Pajares, 1996b, 2006; Pajares \& Schunk, 2001; Phan, 2013b; Schunk, 1995; Schunk, Pintrich, \& Meece, 2008), since Bandura's (1977) seminal paper (titled: "Self-efficacy: Toward a unifying theory of behavioral change"), to attest to the potency of this theoretical construct in educational and non-educational contexts.

The quest then, in this analysis, is for us to consider the utilization and implementation of Bandura's (1997) theoretical tenets in academic and non-academic settings. Our examination of the empirical literature scopes an in-depth discussion and analysis of studies that have been conducted in achievement contexts. This synthesis and overview of personal self-efficacy, in particular, deliberates a number of objectives for educators and researchers to consider, for example: (i) why is there a need for us to promote quality learning and positive learning experiences in secondary schooling?, (ii) what is the role of personal self-efficacy in educational and non-educational settings?, and (iii) what areas of personal self-efficacy may we advance for further research development?

\section{The Status Quo: A Need to Achieve in Learning}

There is no denying that academic excellence in schooling is a feat for recognition and implementation (Phan, 
2013b). From a proactive perspective, for example, exceeding academic achievement in secondary schooling has substantial effects on individuals, such as cognitive transformation and consideration of positive future anticipations (e.g., "What do I want to do next after Year 12? Maybe I'll go to university like my sister, Mary") and planning of career choices, post-secondary (e.g., "I want to be an electrical engineer like my father")(Betz \& Hackett, 1983; Vázquez \& Rapetti, 2006). A desire to achieve in motivational contexts, in this analysis, entails academic resilience (e.g., "I think I'm good at dealing with schoolwork pressures": A. Martin, 2002; A. J. Martin \& Marsh, 2006, 2008) and modest effort expenditure, enabling individuals to engage in deep cognitive strategies for learning (e.g., "I try to relate new material, as I am reading it, to what I already know on that topic": Kember, Biggs, \& Leung, 2004). Academic achievement for success, in essence, precipitates a selection of cognitive processes (e.g., effort expenditure) that facilitate quality learning and enriched experiences. Academic resilience, in particular, is of significance as it instills a set of characteristics that define individuals' cognition and behaviors in various learning contexts (Dweck, 1999). Dweck's (1999) theoretical overview, for instance, has yielded some crucial information pertaining to resilience in educational settings. A heightened sense of resilience, in contrast to helplessness, entails individuals to seek out challenging tasks with a view towards mastery and personal improvement. Resilient individuals tend to view effort as pivotal in the accomplishments of learning tasks. Success or failure is attributed internally to one's own effort expenditure (e.g., "I can see why I failed last time; I didn't put too much effort at all"), rather than ability or "intelligence" per se. If this is the case, then from an educational perspective, we would want to design and develop a system that could facilitate and encourage a resilient frame of mind (King, 2006).

In some societies and cultures, a motive to achieve may entail intrinsic emphases, such as moral commitment to assist others to learn and fulfill their short-term goals and learning objectives (Phan, 2013b). Some Indigenous groups, for instance, are more inclined and/or compelled to engage in communal learning in order to share altruistic values and beliefs with others. This notion of collectivism (Markus \& Kitayama, 1991; Triandis, Bontempo, Villareal, Asai, \& Lucca, 1988), in contrast to individualistic thinking, dictates an ideology of group accomplishments and non-evaluative practices (Phan, Maebuta, \& Dorovolomo, 2010). Individuals, by means of sharing information and caring for others, experience a sense of cultural identity, affiliation, and belongingness to a community (Phan, In press-2013). Individualism, differing from connectedness and communalism, espouses a motive for individual success, based on reasons such as a need to achieve for recognition, pride, and family values (Phan, et al., 2010). The Asian ethos (e.g., filial piety: Chow \& Chu, 2007), for example, embraces the importance of family, and philosophical beliefs that accentuate commitment, duty, and honor. Individualistic learning and achievements may also extend to include other deliberations, such as mastery and individual growth of personal competence (e.g., improving literacy skills), and an appreciation and valuing for learning tasks (e.g., "I think I will be able to use what I learn in this unit in other units": Pintrich, Smith, Garcia, \& McKeachie, 1993) and other extracurricular activities (Hulleman, Durik, Schweigert, \& Harackiewicz, 2008; Liem, Lau, \& Nie, 2008), etc.

From a maladaptive perspective, in contrast, academic mediocrity is also of a pressing concern and significance for educators, with negative outcomes observed in both educational and non-educational settings (Finn, Gerber, \& Boyd-Zaharias, 2005; Henry, Knight, \& Thornberry, 2012; Salamonson, Andrew, \& Everett, 2009; Suárez-Orozco, Pimentel, \& Martin, 2009). In educational contexts and schooling, for example, low academic achievements entail pessimistic feelings and negative future anticipations (e.g., "I really don't see much of a future for myself')(Adelabu, 2008; Phan, 2009b; Seijts, 1998; Vázquez \& Rapetti, 2006), hope (Snyder \& Shorey, 2002; Snyder, et al., 2002), and inclination towards work-avoidance behavior (e.g., "I want to do as little work as possible": Harackiewicz, Barron, Carter, Letho, \& Elliot, 1997). It is not unexpected, similarly, that academic failures also coincide with other negative achievement-related outcomes, such as a weakened sense of academic self-beliefs (e.g., self-efficacy beliefs: Bandura, 1977a, 1997), a lack of resilience, and minimal effort expenditure in learning. Wider implications, in this analysis, connote a positioning in low paid jobs and modest standing in society for individuals.

From a non-educational perspective, low quality learning and academic failures encompass a number of facets that have long-term consequences for individuals and their families. Notably, as previous empirical evidence indicates, indicative of low achievements in educational settings is the noting of academic disengagement (Henry, et al., 2012; Salamonson, et al., 2009; Suárez-Orozco, et al., 2009) that results in school dropout, delinquency, problem substance abuse, and participation in criminal and antisocial behaviors (Henry, et al., 2012; Moretti, 2005). Coupled with this emphasis, of course, is an observation that many of these individuals have low academic and non-academic aspirations and anticipations in life. This analogous association is not uncommon, given that academic excellence serves as a portal for economic vibrancy and social mobility. The latter 
non-academic facets (e.g., problem substance abuse), in particular, are of a major concern, as these often have lasting and detrimental effects on individuals (Henry, et al., 2012; Rouse, 2005; Woolf, 2007). On-going cycles of academic failures in schooling perpetuate and may lead to feelings of despondency, providing limited avenues for future anticipations and aspirations. Our work involving students in developing countries (Phan, 2008; Phan \& Deo, 2007, 2008) has shown, for example, that poverty as a recurring experience often transforms into pessimistic projections about one's own future (e.g., "My future looks pretty bleak..."). This personal journey of hardship and despair tends to escalate and, in many cases, there is little avenue for individuals to ascertain academic qualifications and/or optimistic outcomes (Phan, 2013b).

The intricacy of the matter discussed (e.g., low academic aspirations) also emphasizes, similarly, other negative lasting outcomes, such as a weakened sense of self-esteem (Dodgson \& Wood, 1998; Lane, Jones, \& Stevens, 2002) and self-concept (Bong \& Skaalvik, 2003; Marsh, 1993; Marsh, Craven, \& Debus, 1991). Cognizant of this potency, we need to focus on individuals' self-image and worthiness and their sense of livelihood for both short-term and long-term outcomes. There is a continuous motive and need for individuals to experience contentment, satisfaction, accomplishment, etc. Achievement per se in schooling, in this analysis, is more than just a prediction and enhancement of one's own aspirations for the future. Rather, success and enriched learning experiences serve to assist and sustain one's self-concept - for example, "I feel pretty good about myself and what I want to do next".

From the aforementioned emphases, it is important for us to consider policies, strategies, and innovations that could, in turn, encourage and facilitate positive learning experiences. Again, similar to our previous mentioning, there is substantial research to advocate for the use of theoretical tenets to promote and enhance equality learning in achievement contexts (Phan, 2013b). The structuring of the classroom social milieu, instilling a mastery goal structure (e.g., emphasis on personal growth of skills), for example, has been considered and noted by a number of scholars and educators (Urdan, 2004). In this analysis, utilizing a number of psychosocial facets available (e.g., teacher's personal characteristics), it is possible for teachers and educators to emphasize the saliency of mastery and quality learning. Instructional policies that indicate the saliency of non-evaluative and non-competitive criteria may instill confidence and favorable perceptions about the purpose of learning (e.g., "Why do I need to spend two school terms learning Calculus?").

There is credence, as we have indicated previously, for the study of theoretical and practical approaches that could assist in the building of a better nation. This avenue of inquiry and development is an ambitious undertaking, entailing theoretical visions and proposals for continuing research development. We need to consider how educational psychology theories could transform into effective practices for both educators and teachers to implement for effective learning. One notable theory, social cognition (Bandura, 1986) and its related theoretical tenet, personal self-efficacy (Bandura, 1997), is quite effective in its explanatory power to explain human cognition and behavior. There is extensive research (Bandura, 1997; Pajares, 1996b; Phan, 2013b; Schunk, 1995), to date, to indicate the significance of self-efficacy in educational and non-educational settings. In this section of the article, we explore the significance of self-efficacy and its scope in the enhancement of positive learning experiences for individuals. The discussion, in particular, entails the situational placement of self-efficacy beliefs within sociocultural settings and their related attributes. We consider, for example, the work of Markus and Kitayama (1991) and its emphasis on the notion of interdependency. In this analysis, some questions that we may ask include, for example: how does a sense of collective self-efficacy influence individuals to partake actively in their social milieus?

\section{Social Cognitive Theory: The Case of Personal Self-Efficacy}

Social cognitive theory (Bandura, 1986, 2002) extends Bandura's (1977) social learning theory, and emphasizes the important tenet of reciprocality between three major classes of determinants: behavior, personal factors (e.g., cognition, affect, and biological events), and the environment (Bandura, 1997; Pajares, 1996b). One clear example arising from this theoretical model of reciprocal determinism involves, say, an individual's own attainment in mathematics (e.g., a recent result in a mathematics quiz). Interpretation of failure (e.g., "Why did I fail the last two quizzes for this topic, Calculus?") may inform and alter an individual's environmental settings and his/her self-beliefs, which in turn inform and change their subsequent performances (Pajares, 1996b). Bandura's (1997) theoretical tenets emphasize, in particular, the importance of self-referent thoughts that enable individuals to evaluate, make judgment, and alter their thinking and behavior (e.g., "I realize that superficial learning does not work with this subject; I need to spend more time taking down notes to prepare myself").

Personal self-efficacy, defined as "beliefs in one's capabilities to organize and execute the courses of action required to produce given attainments" (Bandura, 1997, p. 3), is an important self-evaluation process that 
influences individuals' behaviors - for example, the choice that one makes in life (e.g., an individual opting to study a vocational course). Furthermore, self-efficacy assists individuals in their mobilization of effort on a learning activity, resilience in the face of adverse situations, and persistence when confronting obstacles. Self-efficacy, according to Bandura (1997), also influences individuals' thought patterns and emotional reactions - for example, a weakened sense of self-efficacy entails a perception that things are tougher than they really are, leading to stress, depression, and a restricted view as to how one would solve a problem (Pajares, 1996b). A heightened sense of self-efficacy, in contrast, creates the feeling of serenity when one approaches difficult tasks and activities. In summation, from this theoretical tenet and emphasis, Bandura (1997) contends that self-efficacy features prominently in human agency.

The characteristics and operational nature of self-efficacy differ from other self-beliefs constructs (e.g., self-esteem)(Bong \& Skaalvik, 2003; Pajares \& Schunk, 2001). Self-efficacy is relatively unique for its emphasis that pertains to the notion of task and domain specificity. Self-efficacy, in this analysis, is not a generic self-belief that stipulates a sense of confidence towards some unknown task (e.g., "I feel confident that I can do things"). Rather self-efficacy, as a noncognitive construct, situates judgments of capability in specific contexts, such as the perceived competence for one to solve a set of problems in Algebra (e.g., "I feel confident that I have ability to solve these 10 Algebra problems involving an unknown $x$ "). Consequently, because of this important characteristic of specificity, self-efficacy is more predictive and explanatory of future performance outcomes than other self-beliefs constructs (e.g., self-esteem)(Bandura, 1997; Pajares, 1996b).

Personal self-efficacy, according to Bandura (1997), is formed from four major sources of information, in their order of potency: enactive learning experience (e.g., repeated successes in mathematics), vicarious experience (e.g., observing a more competent peer), verbal persuasion (e.g., receiving attributional (e.g., ability) feedback) and emotional and physiological states (e.g., a heightened state of anxiety). There is clear and consistent evidence, arising from quantitative research studies (Britner \& Pajares, 2006; Lent, Lopez, \& Bieschke, 1991; Lopez \& Lent, 1992; Pajares, Johnson, \& Usher, 2007; Phan, 2012a), to indicate that individuals rely predominantly on prior achievements to formulate and develop their self-efficacy beliefs for academic learning. Our own longitudinal research investigations (Phan, 2012a, 2012b), similarly, have yielded some significant findings, such as the trajectories that illuminate the relations between informational sources (e.g., prior learning experience), self-efficacy beliefs, and academic performance in a subject domain. Prior research studies have also reported clear and consistent evidence, attesting to the relations between academic self-efficacy and other achievement-related outcomes, such as perceived usefulness, self-concept, problem-solving skills, and apprehension (Pajares, 1996a; Pajares \& Graham, 1999; Pajares \& Johnson, 1996; Pajares \& Kranzler, 1995; Pajares \& Miller, 1994; Pajares, Miller, \& Johnson, 1999).

Bandura's $(1986,1997)$ social cognitive theory, taking into consideration the potency of personal self-efficacy beliefs has been acknowledged to make theoretical and practical contributions in educational and non-educational settings. As we have alluded previously, there is continuous research to indicate that self-efficacy relates to other cognitive (e.g., deep learning strategies) and noncognitive (e.g., self-esteem) processes (Pajares, 1996b; Phan, 2013b; Schunk, et al., 2008). Self-efficacy beliefs, in conjunction with interrelatedness involving cognitive and noncognitive processes, influence quality learning in achievement contexts. More recently, from a cognitive-motivational perspective, there is an interest in the study of non-learning, non-achievement outcomes. Bandura's (1997) published work, for example, emphasizes the impact of self-efficacy in health functioning and other related, non-academic functions (Alessandri, Caprara, Eisenberg, \& Steca, 2009; Odgers, et al., 2009). Our own qualitative study (Phan, In press-2013), recently, yielded evidence to show that Bandura's (1997) theoretical tenets could explain and feature in peace and nation building. In a similar vein, the question is how and to what extent personal self-efficacy beliefs assist secondary school students in non-academic outcomes (e.g., positive peer engagement). In this section of the article, we explore self-efficacy and its situational placement and explanation in non-academic settings. We explore and discuss, for instance, the impact of self-efficacy for future short-term and long-term outcomes, such as the formation of a stable identity, proactive career projections, etc.

\section{Identity and Engagement}

Quality learning in achievement contexts is more than just a reflection in obtaining good academic results and grades (e.g., "I received, on average, a mark of 78 for the last six quizzes")(Phan, 2013b). Of course, as we expect from societal and parental expectations and criteria, high academic achievements (e.g., GPAs) are often required for a number of purposes, such as entry into university and/or selecting a career choice (Betz \& Hackett, 1983). In a similar vein, academic achievements may also serve to enhance individuals' courses of actions in situations other than those that accentuate academic excellence and educational aspirations (e.g., "I want to do 
Calculus II next year and major in ..."). This emphasis, in our view, is important and may have wider implications for educators and individuals who may have limited academic capabilities. This line of thinking, as we alluded earlier, accentuates the importance of long-term commitment and outcomes for individuals. We need to consider, as educators, instructional policies, practices, and other means that could cultivate a climate for positive cognitive, personal, and social development.

We contend, drawn from our previous research studies (Phan \& Deo, 2007, 2008), that other non-academic achievement facets may also emphasize extensive needs for us, as educators, to consider. In the context of this article, in particular, we focus on disadvantaged secondary school students, who may experience financial and social hardship, learning difficulties, family problems, etc. This emphasis of issues that relate to social and cultural disadvantages may enable us, in turn, to explore how social cognitive theories (Bandura, 1986), notably personal self-efficacy (Bandura, 1977a, 1997) could feature and explain positive outlook and anticipatory thoughts, and enriched learning experiences. In this analysis, for continuing research development and consideration for applied instructional practices, we make attempts to situate personal self-efficacy within the contexts of society, the community, and family (Phan, 2012c). How does self-efficacy, for example, influence or facilitate an individual's standing within a local community?

In the discussion of quality learning and its cultivation in secondary school settings, we need to take into consideration the significance of students' identities and their sociocultural status and positioning within a community or society (Phan, In press-2013). An individual's notion of identity espouses, in part, beliefs that pertain to a sense of belongingness and affinity. Identity also, in this analysis, relates to one's own affiliation with a cultural, ethnic, or social group of individuals who may, in effect, share a sense of collectivism (Adelabu, 2008). As individuals living in a local community, for example, we may identify with others, and share a number of psychosocial and/or cultural attributes (e.g., personal ethos) that define us as a "common" group. For example, secondary school students going through a period of adolescence (Erikson, 1968) may query their own positioning, relationship, and kinship with others (Phan, 2010b). Some students may ponder, reflect, and pose personal questions such as "Who am I as a person?" and "What do I want to do next in life?" to formulate their perceptions and ideals about identity status (Phan, 2012c). Answers to these questions and other related issues may provide a basis for students in secondary schools to contemplate their statuses and futures in life.

By the same token, from a wider perspective, individuals in general may also query their cognitive and social functioning within a community or society (Phan, 2009a, In press-2013). This consideration may entail, similarly, a number of questions that could, in turn, reflect individuals' sense of reception and affiliation with others (e.g., "What is my relationship with my peers in this community?"). Positive experience and perception of well-being and acceptance (e.g., "I feel pretty good that everyone seems to like me and accept who I am, as a person") may, in fact, facilitate proactive engagement in school and the community, in general (Phan, 2012c). Our previous work (Phan, 2008, 2012c, In press-2013; Phan \& Deo, 2007) and others (e.g., Adelabu, 2008; Vázquez \& Rapetti, 2006), for example, has yielded some important theoretical and empirical evidence, suggesting that our sense of identity (e.g., Who we are as people, perhaps?) may situate and develop within sociocultural settings and historical genesis (e.g., a child born into an impoverished family, compared to another child who may be more privileged). From a non-academic and social perspective, in this analysis, the notion of an embedded identity connotes other positive-related outcomes, such as heightened self-esteems (e.g., "I feel pretty good about myself') and experiential feelings of morality. The latter emphasis is rather unique and relates closely to some cultural groups (Phan, et al., 2010; A. D. Ravuvu, 1988; Teaero, 2002), wherein there is a strong ideology and acceptance of sharing, caring, and looking out for others' social and moral well-being. Positive affect, confidence, and the knowing of one's own identity (e.g., "I know who I am and what I want to do in life") may play an important role in the formation of relationships with family members, peers, adults, etc.

We need to consider the potency of individuals' own positioning within a society and/or moment in time. Identity and, of course, feelings of belongingness and social and personal well-being may associate and dictate individuals' cognitive time structures in educational and non-educational settings (Phan, 2012c). The espoused sense of stability in one's life, arising from the forming of a positive identity may assist in his/her anticipation of both short-term and long-term objectives and goals in life (e.g., "Everyone thinks highly of me in this community; I think I will do something in leadership and management to assist these people"). A community that is stable in its social and political fabric may provide more grounding for individuals to feel confident and connected. Social acceptance and experiences that pertain to kinship and affiliation by cultural similarities (e.g., personal ethos in achievement) may, for instance, allow individuals to engage with others (e.g., teachers) towards the achievement of enriched outcomes, such as contemplation of a career choice.

The question, though, is what happens when some individuals do not connect with others, or who have low 
self-beliefs in their sense of identities? This emphasis is rather prominent, especially for those individuals who in the minority and face constant racial and social discrimination, ethnic profiling, and poverty (Phan, In press-2013). Similar to our previous theoretical contention, a sense of coherent identity is in this case an important element for consideration. We would expect, in this analysis, for an unpleasant and unjust society to exacerbate a sense of uncertainty in terms of identity formation. An intolerant community, for example, is more likely to cultivate a sense of turmoil and instability, leading 'perceived' minority individuals to feel disconnected and disfranchised with society at large (Phan, 2009a). Many minority individuals who are unsure of their social standing may experience feelings of hopelessness and arising from this premise, of course, is a lack in confidence of one's own identity status (e.g., "I'm not really sure of myself, don't know what to do next"). By the same token, a weakened sense of identity may also result in a number of negativities, such as school disengagement and school dropout (Fredricks, Blumenfeld, \& Paris, 2004), maladaptive practices in schooling (e.g., adoption of work-avoidance goals: Harackiewicz, et al., 1997), low, unproductive future anticipations (e.g., an individual not knowing what to do in life), participation in criminal and antisocial behaviors, etc.

In daily educational settings, for secondary school students, an epic proportion may arise from a dysfunction in personal and social relationships. Economical, political, and social disadvantages for some individuals (e.g., financial constraints) may have lasting effects, beyond secondary and post-secondary schooling. Apart from school disengagement, we need to consider the fact that the social milieu at large may also shape and influence individuals' decision-making beyond their classroom learning. We contend that other achievement-related facets are of significance and require research advancement, such as participation in active and democratic citizenship, future academic aspirations and career choices in life (e.g., "I would like to work hard and consider a career choice in aeronautical engineering"), an embracement in mastery and quality learning (Phan, 2013b), an appreciation in relationships with family members and peers, etc. Consequently, from our theoretical positioning, there are implications that extend beyond the realm of achieving a good grade in quizzes, classroom assignments, etc. This argument posits the notion that there is more at stake other than academic competence in a subject domain.

Our theoretical proposition, as indicated in the preceding sections, suggests that there is interconnectedness between an individual and his/her social milieus. By the same token, the aforementioned emphases indicate that there is more in academic learning than just the immediate proximity of time and space. From the perspective of educators, for instance, there is a paradigm shift in our thinking of academic learning and success in secondary schooling and beyond. The sociocultural embedding of individuals within multilayers of society, as advocated by some researchers (Bronfenbrenner, 1989; Okagaki, 2001; Phan, 2012c), implies that personal learning experiences may extend to influence others. The triarchic models of individualized cognition, as proposed recently (Okagaki, 2001; Phan, 2012c, 2013b), indicates there are different psychosocial (e.g., family pressure to succeed) and ethno-historical facets (e.g., cultural ideology) that could shape our well-being, academic learning and achievements, and personal relationships with others. This theoretical contention, although requiring additional empirical research examination, entails a larger system of change and influences between society, family, individuals and their choices in life. From a larger, sociocultural perspective, for example, we contend that extraneous factors from society and the community, in general, would shape individuals' beliefs and motives for learning and achieving. A technological, advanced society, as an example, would compel individuals to think and behave in a competitive manner, resulting in an ideology that emphasizes academic excellence and competition. Families situated in these social and economical climates would, similarly, adopt certain ethos and practices that differ from cohorts in other settings.

It is important then, in this analysis, for us to query the extent to which personal self-efficacy beliefs (Bandura, 1977a, 1997) could make an impact on individuals' well-being and their learning in sociocultural contexts. Individuals' well-being, in this case, may entail a wide range of non-achievement outcomes, such as positive feelings, emotions, and a sense of hope. There is empirical research (Alessandri, et al., 2009; Lowe, et al., 2008), yielding consistent evidence to highlight the interrelations between self-efficacy and other well-being variables. The work of Lowe, et al. (2008), for example, showed that arthritis self-efficacy beliefs influenced the relationships between coping and emotional outcomes. Similarly, Alessandri, et al.'s (2009) longitudinal study reported some significance in findings in relation to Bandura's (1997) theoretical tenets. In particular, across three points of data collection, the authors found that individuals' perceived self-efficacy beliefs in handling emotions (including the regulation of negative emotions and the expression of positives)(e.g., "How well can you keep from getting discouraged by strong criticism?") influenced their self-efficacy beliefs to empathize with others (e.g., "How well can you experience how a person in trouble feels?"), which, in turn, impacted on pro sociality (e.g., "I try to help others"). Our own recent longitudinal research study (Phan, 2013a), using latent 
growth modeling (Bollen \& Curran, 2006; Hancock \& Lawrence, 2006; McArdle \& Nesselroade, 2003) has found, speculatively, that some internal cognitive processes and/or extraneous factors could account for the instability of both academic self-efficacy and hope. Hope, similar to self-efficacy, is an important construct that may assist us in our understanding of human behavior. Its empirical examination has been relatively modest (Adelabu, 2008; Snyder \& Shorey, 2002; Snyder, et al., 2002) in comparison to self-efficacy beliefs in educational settings.

The emphasis outlined in the preceding sections connotes, possibly, the contributions of self-efficacy beyond microanalytical assessments and criteria (e.g., the perceived competence for one to solve a set of problems in Algebra). In terms of practices and continuing research development, for example, we need to consider a wide range of educational and non-educational implications that may arise from this theoretical positioning. In this section of the article, we explore some major implications that arise from the theory of social cognition (Bandura, 1977b, 1986), paying close attention in particular to the tenets of self-efficacy (Bandura, 1977a, 1997) in various settings.

\section{Implications for Research Development and Practices}

The tenets of social cognition (Bandura, 1986) have been noted to explain and predict individuals" learning and behaviors. In our discussion of human agency, we need to acknowledge that there is a more to academic success than just classroom achievements in various subject domains. The notion of quality learning, from our theoretical perspective, entails a number of short-term and long-term outcomes for individuals. These implications range from an interest in mastery of skills to school engagement and active and democratic citizenship in society. Ultimately, as educators and researchers, one major objective for us is to cultivate a climate and mentality that would emphasize and facilitate intellectual curiosity, task valuing and appreciation for learning, school engagement, and the ability and keenness to anticipate career choices, etc. Psychologically, as the extensive literature has attested, there are theoretical orientations such as Future Time Perspective (FTP)(De Volder \& Lens, 1982; McInerney, 2004; Mehta, Sundberg, Rohila, \& Tyler, 1972; Phan, 2009a; Seijts, 1998), Student Approaches to Learning (SAL)(Biggs, 1987; Entwistle \& Tait, 1994; Marton \& Säljö, 1976), and Reflective Thinking (Deo \& Nabobo, 2003; Dewey, 1933; Grushka, McLeod, \& Reynolds, 2005; Schön, 1983) that may account, predict, and encourage enriched learning experiences in achievement contexts. Personal self-efficacy (Bandura, 1997), as outlined previously, is a noncognitive psychological construct that may enhance individuals' cognition, affect, and behaviors.

In relation to Bandura's (1997) theoretical tenets of personal self-efficacy, we realize there are a number of questions and queries that researchers could pursue. For example, considering the wide range of achievement-related outcomes that may relate to individuals' learning, the main question is how does self-efficacy fit in with individuals' functioning (e.g., social interaction with peers) within a society at large? How does self-efficacy facilitate civics and active citizenship? These questions, in our view, are of significance, and highlight the extent to which self-efficacy beliefs may extend to impact on outcomes other than achievements in class (e.g., obtaining an "A" grade for Calculus). Our contemplation of self-efficacy in this article is rather interesting, as it entails the notion of "generalization" of self-efficacy beliefs beyond the realm of execution of academic tasks (e.g., perceived competence to solve 10 Algebra problems involving an unknown $x$ ) and problems in a subject area (Bandura, 1997; Pajares, 1996b).

The scope of our theoretical contention emphasizes two major points: (1) the use of self-efficacy to enhance individuals' engagement in schooling and other-related activities (e.g., planning a career choice), and (2) the cultivation of individuals' identities and relations with others via means of self-efficacy beliefs. This proposed positioning is relatively unique as it attends to the notion that self-efficacy beliefs may function beyond the efficiency of classroom learning. This proposition entails the facilitation of general 'life-impact' decision-making (e.g., career choice) and related outcomes on individuals, via means of self-efficacy beliefs. Our argument contends, specifically, an approach to self-efficacy that focuses on the non-microanalytical assessment and preference of this construct (Bandura, 1997; Pajares, 1996b). As an example to this methodological approach of assessment, we could instill and draw self-judgments of competence such as, "I feel confident that I have the necessary social skills (e.g., personal relationship) to plan a career path for myself for the next five years". For school engagement, similarly, we could situate self-efficacy to a wider context, depicting in this case its impact on general school engagement (e.g., getting along with peers) and post-secondary trajectories (e.g., employment prospect).

From a non-specific task perspective (e.g., self-belief about solving 10 mathematics problems in Algebra), self-efficacy may have wider, non-academic and academic implications. Our theoretical positioning, in this 
analysis, entails the promotion of personal self-efficacy to make an impact on behaviors and achievement-related outcomes that extend beyond the realm of problem solving. We need to consider, for example, the instilling of self-efficacy beliefs such as, "I feel I have the competence to find various aspects (e.g., sports) of schooling interesting" and "I feel I have the competence to make an effort to enjoy schooling". This cultivation of self-efficacy may assist individuals to plan, project, and envisage more positive long-term anticipatory outlooks (e.g., "I'm okay with schooling; maybe in four or five years time, I will consider going to university"). We do not discount, though, the importance of classroom learning and one's ability to deal with activities, tasks, or problems. What we are advocating, however, is the need and consideration to embrace self-efficacy at a more global level. The question then, from the approach of applicability, is how we go about encouraging and enhancing positive self-beliefs.

\subsection{Periodic Assessments of Personal Self-Efficacy}

The use of personal self-efficacy (Bandura, 1977a, 1997) to mediate and facilitate positive behaviors and long-term outcomes (e.g., selection of a career choice) is an important feat. We need to consider, then, the different strategies that could promote and enhance positive self-efficacy beliefs. An immediate, situational self-belief that stipulates a particular moment in time is not the preferred option or pathway (e.g., "I feel right at this moment that I have the perceived competence to solve this set of Calculus problems"). We would want to, from a post-secondary schooling perspective, cultivate continuous heightened self-beliefs over the course of time. We do acknowledge, though, that personal self-efficacy beliefs change and are not stable (Bandura, 1997). Despite this instability and contextualization of self-efficacy, it is still worthwhile to encourage individuals to feel self-efficacious about their daily lives. The significance of our trajectories, especially upon post-secondary schooling (e.g., deciding what to do after Year 12) warrants a serious consideration.

Periodic gauging and assessments of self-efficacy may encourage and facilitate positive convictions that one has the ability and capability to succeed schooling in terms of quality learning, achievements, enriched schooling experiences, social interactions, etc. Setbacks are normal and unstable; things can change for the better. Continuous feedbacks, informal conversations after lessons, and formal instructional policies may serve as a basis to assist students in their self-beliefs about schooling. Instructional policies that emphasize and acknowledge extracurricular and social activities, for example, may instill positive self-efficacy and appreciation for learning and schooling, in general. Self-efficacy for academia, in this analysis, entails more 'non-specific' emphases, rather than specific contexts such as the solving of Calculus problems. Highlighting the proactivity of non-academic activities in schooling (e.g., planning and taking part in a school fete), for example, may inform and enlighten students that there is more to academia than just classroom learning and achievement. Schools and education institutions, as a whole, may provide input and encouragement via means of having periodic activities and events that accentuate their significance. Less-academic minded students, who value social goals, in particular, may appreciate the emphases pertaining to school fetes, sport activities, etc.

Interests and valuing in achievement-related tasks and social activities and events may, consequently, have long-term significance for students. For example, in relation to Bandura's (1977, 1997) theoretical tenets, appreciation of non-academic priorities (e.g., assisting other students to fulfill their goals) may instill positive self-beliefs and conviction. Heightened self-efficacy beliefs, from a global context (e.g., "I feel confident that I have the competence to take part in social school activities and events"), for example, may assist secondary school students to approach non-academic tasks and priorities with a sense of confidence and conviction. Such self-efficacy beliefs may, in this analysis, transcend to other domains of functioning (Bong, 1997, 2002) and long-term outcomes. One domain of functioning, for instance, entails a continuing regard for any form of schooling that may result in corresponding long-term outcome(s).

\subsection{Appropriate Role Models}

The strengthening of personal self-efficacy may include the use of appropriate role models (Bandura, 1986, 1997). There is extensive experimental research (e.g., Schunk, 1987; Schunk \& Hanson, 1985, 1989a, 1989b; Schunk, Hanson, \& Cox, 1987) that shows the potency of role models (e.g., a sports personality) in self-efficacy. Similarly, there is clear and consistent evidence from correlational research, utilizing Likert-scale inventories (e.g., "I have a close friend who is excellent in (subject)": Phan, 2012b) that attests to the impact of observational learning and social comparison on self-efficacy beliefs for academic learning (Hampton, 1998; Lopez \& Lent, 1992; Matsui, Matsui, \& Ohnishi, 1990; Phan, 2012a). Regression analyses and structural equation modeling have yielded findings that illuminate the positive effect of vicarious experience on self-efficacy beliefs. Vicarious experience, derived from observation and social comparison, in this analysis, has relevance for secondary school teaching and learning. In the contexts of the upper secondary school period, exposures to effective role models 
are of significance in terms of academic learning and appropriate behaviors. We note that some inappropriate role models, for instance, may impart non-effective information, resulting and perpetuating in antisocial behaviors and criminal activities. Non-competent, academic individuals, similarly, may also inform others that not much may be expected of them.

We need to take into consideration, then, the importance of vicarious experience in classroom teaching and learning. Foremost, in relation to Bandura's $(1986,1997)$ social cognitive theory, it is prudent that we expose secondary school students to appropriate role models. Scholarly models, such as capable peers and adults (e.g., "Look at Thomas, everyone; Thomas has managed to master this topic and he's doing quite well in the last three quizzes") may provide fruitful information and benchmark for students to note and acquire. This information (e.g., observing a peer who is doing well in his/her studies for a topic), as outlined in Bandura's (1997) theoretical tenets, is pivotal as it instills conviction and self-beliefs that one is also capable (e.g., "Thomas is like me; if he can do it, then I know I can do it too!"). From a more generalized perspective, we contend that self-efficacy beliefs, in this case, do not necessarily have to reflect task and problem-specificity (e.g., the perceived competence to solve the following questions in Calculus). Similar to our previous positioning, appropriate role models may impart information relating to schooling and engagement, at large. Achievers who have strong social and moral goals (e.g., a school prefect's desire to assist new students settle in), for instance, may relay potent messages to others to achieve similar objectives and goals.

\subsection{A Collective Sense of Identity}

A sense of identity, as we discussed previously, has profound impact on individuals in terms of their relationships and future behaviors. Notably, from a non-academic perspective, a sense of identity (e.g., "How do I relate to this community?") may enhance individuals' personal well-being, self-esteem, and social development. Identity and interpersonal relationships with others may enable individuals to function effectively within a society and community. As educators within a larger system of change (Bronfenbrenner, 1979, 1989), there is a social and larger motive for us to assist individuals to better their lives with a sense of self-worth and dignity (Bandura, 1997). There is then, accordingly, an intrinsic desire for society, in general, to enable individuals to function effectively.

From a more global perspective, it is important to recognize that social acceptance and affiliation make a major contribution in the shaping of individuals' cognition and behaviors within a community. In some indigenous societies, for example, the notion of acceptance and belongingness facilitates and promotes experiential feelings of caring, sharing, and collectivist thinking (Nabobo, 1998; Nabobo-Baba, 2006; Phan, 2012c; Phan, et al., 2010; A. Ravuvu, 1983). There is stronger affiliation, in this analysis, with sociocultural attributes, such as the sharing of knowledge and caring for others. More importantly, however, a sense of belongingness and relatedness to others may cognitively transform individuals' thinking and beliefs towards a collective anticipation of short-term and long-term goals for fulfillment. For individuals who are non-academically minded, and those who have weakened self-efficacy beliefs for academic learning, the emphasis pertaining to inclusiveness and cultural acceptance may serve to their social well-being and other non-achievement related facets.

We need to take into consideration the significance of collectivism (Markus \& Kitayama, 1991; Triandis, et al., 1988 ) and its related implications for individuals. Rather than individualistic thinking and behavior, a sense of interdependency may entail a number of beneficial attributes. Considering Bandura's (1997) social cognitive tenets, in particular, the notion of collective self-efficacy, defined as "a group's shared belief in its conjoint capabilities to organize and execute courses of action required to produce given levels of attainments" (Bandura, 1997, p. 477), may provide a basis for individuals to attain non-individualistic objectives and goals. Perceived collective self-efficacy, in our view, may serve to facilitate other well-defined facets, such as enabling and preparing societies for sociocultural changes. In relation to our previous discussion relating to identity status and school engagement, collective self-efficacy beliefs towards academic and non-academic criteria may encourage and/or promote shared feelings of hope, idealism, and joy and fulfillment in objectives, goals, etc. What we could do, for example, is to structure learning activities (e.g., group investigation) and social events (e.g., school term fete) that accentuate and encourage group connectedness, interdependency, and belongingness. Often the case, in many secondary schools in metropolitan areas, occasional "multicultural" days on Fridays for students and teachers alike may promote collegiality, friendships, and cultural acceptance and values for others. Sport carnivals and the creation of "Teams" or "Houses", based on students' surnames, may also stimulate positive psychology (e.g., heightened self-esteem) and achievements of pride, affiliation, and accountability. A student may, for example, feel worthwhile and valued because of his/her contribution towards the success of the team winning a football match. 
Personal self-efficacy in accomplishing a common, shared goal or objective may cognitively transform individuals' thinking and behavior towards interdependency and collaboration. Collective self-efficacy beliefs, according to Bandura (1997), feature prominently in society and nation building, enabling individuals in this process to partake in non-individualistic practices (e.g., political decision making). Our recent research study, qualitative by means of in situ reflections (Phan, In press-2013), yielded some relevant findings, highlighting in particular the significance of collective self-efficacy beliefs. We noted, for example, that tertiary students developed their collective self-efficacy beliefs by means of interactions and social dialogues. More importantly, however, such heightened self-beliefs, collectively, enabled these students to embrace unity and diversities. In a similar vein, reflective of the previous discussion, we noted that group work and collaboration in classes helped students appreciate and value others' perspectives and views about society, etc. This qualitative evidence, although requiring further empirical examination, suggests that university studies entail more than just classroom learning and academic engagement. Rather, in the sociocultural contexts of our study, there was a wider emphasis on cultural and ethnic tensions, tolerance, and harmony.

In terms of instructional and applied practices, we posit that there are pedagogical and non-academic strategies that could be used to encourage and promote collective self-efficacy beliefs. The nature of a subject matter or academic domain may provide a basis for educators to structure their teaching in order to cultivate positive self-beliefs. Most notable, perhaps, is a need for us to create and stimulate a climate of active social dialogues and unity between students, disregard differences pertaining to ethnicity, cultural and religious beliefs, etc. To assist us in this process, we could take into consideration previous theoretical orientations of learning and development (Bronfenbrenner, 1989; Vygotsky, 1978; Wertsch, del Rio, \& Alvarez, 1995). For example, in relation to the various triarchic models of learning and development (Okagaki, 2001; Phan, 2012c), how can a community, in general, mediate individuals' cognition and behaviors towards acceptance for others? How does the interrelationship between two families facilitate their children's relations in school (e.g., peer relationship)? It is plausible, perhaps, to suggest that one's own collective thoughts and self-efficacy beliefs may situate within different levels of society, ranging from the community to the classroom, in general. A community receptive to change (e.g., increasing immigrants settling in) and embraces diversities and differences may foster a social milieu that accentuates a sense of confidence and positive emotions. Some individuals, differing in their personal beliefs or cultural attributes, may participate more willingly in democratic processes if they feel identified and/or welcomed.

In the contexts of schooling, similarly, there is merit for educators to promote collaboration and collective thinking and behavior. One clear example, for instance, is our structuring of goals that emphasize mastery of skills and contents, group participation, and social dialogues. Group investigations and research projects may initiate conflict resolution, and enable students in this process to interact and communicate with each other. Contentious or interesting topical themes, for example, may stimulate discussions and, more importantly, provide a basis for students to listen and respect others' different views, perspectives, etc. The process of engagement, in itself, may instill positive collective self-efficacy beliefs (e.g., "I feel really confident about this group activity; from my point of view, I believe we all have the capabilities to work towards a common goal") and enjoyment for learning. Such heightened self-beliefs may transcend to other wider academic activities and social events (e.g., working together for a "multicultural" event), and consequently, arising from this, students may feel more inclined to engage in schooling. Proactive engagement in academic activities and social events, with a view to appreciate and accept varying views and cultural diversities, combine to constitute the essence of quality learning. Enriched learning experiences in school, in turn, may cognitively transform students to consider other anticipatory projections in life (e.g., planning a career path).

Finally, from an educational perspective, the use of personal self-efficacy as a form of intervention to enhance individuals' learning and positive behaviors is prudent. It is desirable, in this sense, for us to transform theoretical tenets (Bandura, 1977a, 1997) and empirical research (Liem, et al., 2008; Pajares \& Kranzler, 1995; Pajares \& Miller, 1994; Phan, 2010a; Sins, van Joolingen, Savelsbergh, \& van Hout-Wolters, 2008) into effective practices for both educators and learners alike. We need to consider, for example, intervention programs in schools or tertiary institutions that promote and incorporate collective or personal self-efficacy beliefs for academic learning. In secondary school settings, in particular, the use of school activities (e.g., end-of-term school fetes) and authentic learning tasks that have practicality and relevance may stimulate intellectual curiosity and interest for school and academic engagement. Timely exposures to appropriate role models and cultural and historical identities, as advocated by a number of researchers (Schunk, 1987; Schunk \& Hanson, 1985; Schunk, et al., 1987), may foster a sense of self-efficacy towards an appreciation for inclusiveness and diversities. Weekly informal teaching that accentuates the importance of historical figures for their academic, political and societal 
contributions (e.g., Noam Chomsky) may provide fruitful information for classroom dialogues and emulation. Less capable and/or shy students may feel more self-efficacious and confident to partake in exercises that emphasize their roles in school and society. The inclusion of classroom pedagogies and/or learning contents that embrace cultural diversities and social differences (e.g., the history of abacus and its possible use in today's settings) may, importantly, encourage students to accept and welcome those who are disfranchised from school and society, in general.

We could also consider in situ interventions that encourage and foster heightened states of self-efficacy beliefs. The enhancement of collective and personal self-efficacy does not have to include formal teaching and implementation, but rather one of informal dialogues and actions. We contend that, as an extension of Vygotsky's (1978) sociocultural theory of development, periodic engagement and scaffolding by peers and capable others could assist in the enhancement of academic self-efficacy beliefs. The use of group work and social discourse, as we have found from our previous research study (Phan, In press-2013), is beneficial and enable a number of social-related outcomes, such as the promotion of a harmonious society, unity, and peace building. In our qualitative, naturalistic study (Phan, In press-2013), we deliberately structured group composition by means of gender, social class, and ethnic diversities. Through group interactions and active discussions, students developed collective self-efficacy beliefs and positive attitudes toward other cultural beliefs, ideologies, etc. Consequently, we encourage educators and teachers to use group learning tasks and social activities that could stimulate debates, conflict resolution, and ongoing dialogues. It is important to note, though, that a heightened state of self-efficacy does not necessarily have to translate into effective learning and high achievement outcomes. It should not be. Instead, educational programs and social activities that are implemented occasionally may instill positive self-efficacy beliefs and confidence toward a wide range of non-achievement outcomes.

\section{Conclusion}

This theoretical overview emphasized the notion of quality learning and academic engagement. Our theoretical contention, drawn in part from previous research investigations, indicates the importance of secondary schooling and its impact on various facets of achievements, both academic and non-academic. One notable indicator that arises from effective academic and social engagement, for example, is an individual's future projections in life. For example, effective learning and school enjoyment may initiate and encourage individuals to adopt mastery and short-term social goals for accomplishment. More importantly, however, proactive school engagement and appreciation for effective learning may provide a strong basis for positive future time anticipations that entail professional growth and career planning.

We are cognizant that individuals originate, historically, and situate in different sociocultural layers of society. Such differences have wide-range implications, such as individuals' disparate epistemological beliefs, cognitive thinking, self-beliefs, ethos and philosophies (Markus \& Kitayama, 1991; Mugler \& Landbeck, 1997; Phan, 2010b, 2012c). The work of Markus and Kitayama (1991), for example, has highlighted ethos, self-beliefs, and behaviors that emphasize the distinction between individualism and collectivism. In a similar vein, other theoretical frameworks (Bronfenbrenner, 1989; Okagaki, 2001; Phan, 2010b) proposed make attempts to explain individuals' cognitive development, behaviors, and self-beliefs in sociocultural settings. Personal self-efficacy, stemming from Bandura's (1997) social cognitive theory, is an important construct that features in human agency and society. From an educational perspective, in particular, self-efficacy serves to enhance and predict individuals' behaviors and learning in achieving contexts.

Our overview in this article has also scoped a number of conceptualized issues and recommendations for advancement and continuing research development. These suggestions, notably, have implications that transcend beyond classroom settings. The use of perceived self-efficacy, arising from Bandura's (1986) social cognitive theory, in particular, has relevance for both academic and non-academic practices. Considering the wider positioning at large, we contend that quality learning, in general, may transpose to other potent, non-achievement outcomes for individuals - for example, the recognition of a well-informed identity (e.g., "I know who I am and what I should do") and/or motives to consider a career choice that may assist oneself and others. To this end, as we have noted from the empirical literature, the role of self-efficacy is rather advantageous, enabling the transformation of individuals' cognitive and non-cognitive processes into effective and positive behaviors.

\section{References}

Adelabu, D. H. (2008). Future time perspective, hope, and ethnic identity among African American adolescents. Urban Education, 43(3), 347-360. http://dx.doi.org/10.1177/0042085907311806

Alessandri, G., Caprara, G. V., Eisenberg, N., \& Steca, P. (2009). Reciprocal relations among self-efficacy beliefs

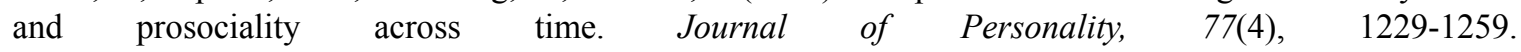


http://dx.doi.org/10.1111/j.1467-6494.2009.00580.x

Bandura, A. (1977a). Self-efficacy: Toward a unifying theory of behavioral change. Psychological Review, 84, 191-215. http://dx.doi.org/10.1037/0033-295X.84.2.191

Bandura, A. (1977b). Social learning theory. Englewood Cliffs, NJ: Prentice-Hall.

Bandura, A. (1986). Social foundations of thought and action: A social cognitive theory. New Jersey: Prentice-Hall, Inc.

Bandura, A. (1997). Self-efficacy: The exercise of control. New York: W. H. Freeman \& Co.

Bandura, A. (2002). Social cognitive theory in cultural context. Applied Psychology: An International Review, 51(2), 269-290. http://dx.doi.org/10.1111/1464-0597.00092

Betz, N. E., \& Hackett, G. (1983). The relationship of mathematics self-efficacy expectations to the selection of science-based majors. Journal of Vocational Behavior, 23, 329-345. http://dx.doi.org/10.1016/0001-8791(83)90046-5

Biggs, J. (1987). Student approaches to learning and studying. Melbourne, Australia: Australian Council for Educational Research.

Bollen, K. A., \& Curran, P. J. (2006). Latent curve models: A structural equation perspective. Hoboken, NJ: Wiley.

Bong, M. (1997). Generality of academic self-efficacy judgments: Evidence of hierarchical relations. Journal of Educational Psychology, 90(1), 102-110. http://dx.doi.org/10.1037/0022-0663.90.1.102

Bong, M. (2002). Stability and structure of self-efficacy, task-value, and achievement goals and consistency of their relations across specific and general academic contexts and across the school year. Paper presented at the American Educational Research Association (AERA). New Orleans, LA, 2002, New Orleans, LA.

Bong, M., \& Skaalvik, E. M. (2003). Academic self-concept and self-efficacy: How different are they really? Educational Psychology Review, 15(1), 1-40. http://dx.doi.org/10.1023/A:1021302408382

Britner, S. L., \& Pajares, F. (2006). Sources of science self-efficacy beliefs of middle school students. Journal of Research in Science Teaching, 43, 485-499. http://dx.doi.org/10.1002/tea.20131

Bronfenbrenner, U. (1979). The ecology of human development. Cambridge, MA: Harvard University Press.

Bronfenbrenner, U. (1989). Ecological systems theory In R. Vasta (Ed.), Annals of child development: Theories of child development: Revised formulations and current issues (Vol. 6, pp. 187-251). Greenwich, CT: JAI Press.

Chow, S. S.-Y., \& Chu, M. H.-T. (2007). The impact of filial piety and parental involvement on academic achievement motivation in Chinese secondary school students. Asian Journal of Counsellung, 14(1 \& 2), 91-124.

De Volder, M., \& Lens, W. (1982). Academic achievement and future time perspective as a cognitive-motivational concept. Journal of Personality and Social Psychology, 42, 566-571. http://dx.doi.org/10.1037/0022-3514.42.3.566

Deo, B., \& Nabobo, U. (2003). Reflections on mixed mode and multimode teaching: USP case study. Paper presented at the 16th Biennial ODLAA Forum, Canberra Australia, Canberra, Australia.

Dewey, J. (1933). How we think: A restatement of the relation of reflective thinking to the educative process. Boston: D. C Health (Original work published in 1909).

Dodgson, P. G., \& Wood, J. V. (1998). Self-esteem and the cognitive accessibility of strengths and weaknesses after failure. Journal of Personality and Social Psychology, 75, 178-197. http://dx.doi.org/10.1037/0022-3514.75.1.178

Dweck, C. S. (1999). Self theories: Their role in motivation, personality, and development. Philadelphia: Psychology Press.

Entwistle, N. J., \& Tait, H. (1994). The revised approaches to study inventory. Edinburgh, Edinburgh University: Centre for Research into Learning and Instruction.

Erikson, E. H. (1968). Identity: Youth and crisis. New York, NY: Norton.

Finn, J. D., Gerber, S. B., \& Boyd-Zaharias, J. (2005). Small classes in the early grades, academic achievement, and graduating from high school. Journal of educational Psychology, 97(2), 214-223. 
http://dx.doi.org/10.1037/0022-0663.97.2.214

Fredricks, J. A., Blumenfeld, P. C., \& Paris, A. H. (2004). School engagement: Potential of the concept, state of the evidence. Review of Educational Research, 74, 59-109. http://dx.doi.org/10.3102/00346543074001059

Grushka, K., McLeod, J. H., \& Reynolds, R. (2005). Reflecting upon reflection: Theory and practice in one Australian university teacher education program. Reflective Practice, 6, 239-246. http://dx.doi.org/10.1080/14623940500106187

Hampton, N. (1998). Sources of academic self-efficacy scale: An assessment tool for rehabitation counselors. Rehabilitation Counseling Bulletin, 41(4), 374-389.

Hancock, G. R., \& Lawrence, F. R. (2006). Using latent growth models to evaluate longitudinal change. In G. R. Hancock \& R. O. Mueller (Eds.), Structural equation modeling: A second course (pp. 171-196). Greenwich, Connecticut: Information Age Publishing.

Harackiewicz, J. M., Barron, K. E., Carter, S. M., Letho, A. T., \& Elliot, A. J. (1997). Predictors and consequences of achievement goals in the college classrooms: Maintaining interest and making the grade.

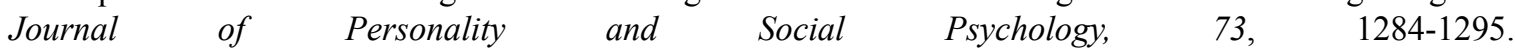
http://dx.doi.org/10.1037/0022-3514.73.6.1284

Henry, K. L., Knight, K. E., \& Thornberry, T. P. (2012). School disengagement as a predictor of dropout, delinquency, and problem substance use during adolescence and early adulthod. Journal of Youth and Adolescence, 41, 156-166. http://dx.doi.org/10.1007/s10964-011-9665-3

Hulleman, C. S., Durik, A. M., Schweigert, S. A., \& Harackiewicz, J. M. (2008). Task values, achievement goals, and interest: An integrative analysis. Journal of Educational Psychology, 100(2), 398-416. http://dx.doi.org/10.1037/0022-0663.100.2.398

Kember, D., Biggs, J., \& Leung, D. Y. P. (2004). Examining the multidimensionality of approaches to learning through the development of a revised version of the learning process questionnaire. British Journal of Educational Psychology, 74, 261-280. http://dx.doi.org/10.1348/000709904773839879

King, L. (2006). Resilience, helplessness, control orientations and set. Retrieved December 30, 2012, from http://www.taolearn.com/articles/article18.pdf

Lane, A. M., Jones, L., \& Stevens, M. (2002). Coping with failure: The effects of self-esteem and coping on changes in self-efficacy. Journal of Sport Behavior, 25, 331-345.

Lent, R. W., Lopez, F. G., \& Bieschke, K. J. (1991). Mathematics self-efficacy: Sources and relation to science-based career choice. Journal of Counseling Psychology, 38, 424-430. http://dx.doi.org/10.1037/0022-0167.38.4.424

Liem, A. D., Lau, S., \& Nie, Y. (2008). The role of self-efficacy, task value, and achievement goals in predicting learning strategies, task disengagement, peer relationship, and achievement outcome. Contemporary Educational Psychology, 33, 486-512. http://dx.doi.org/10.1016/j.cedpsych.2007.08.001

Lopez, F. G., \& Lent, R. (1992). Sources of mathematics self-efficacy in high school students. Career Development Quarterly, 41, 3-12. http://dx.doi.org/10.1002/j.2161-0045.1992.tb00350.x

Lowe, R., Cockshott, Z., Greenwood, R., Kirwan, J. R., Almeida, C., Richards, P., et al. (2008). Self-Efficacy as an appraisal that moderates the copingemotion relationship: Associations among people with rheumatoid arthritis. Psychology and Health, 23, 155-174. http://dx.doi.org/10.1080/14768320601139160

Markus, H. R., \& Kitayama, S. (1991). Culture and the self: Implications for cognition, emotion, and motivation. Psychological Review, 98(2), 224-253. http://dx.doi.org/10.1037/0033-295X.98.2.224

Marsh, H. W. (1993). The multidimensional structure of academic self-concept: Invariance over gender and age. American Educational Research Journal, 30, 841-860.

Marsh, H. W., Craven, R. G., \& Debus, R. (1991). Self-concepts of young children 5 to 8 years of age: Measurement and multidimensional structure. Journal of Educational Psychology, 83, 377-392. http://dx.doi.org/10.1037/0022-0663.83.3.377

Martin, A. (2002). Motivation and academic resilience: Developing a model for student enhancement. Australian Journal of Education, 46(1), 34-49.

Martin, A. J., \& Marsh, H. W. (2006). Academic resilience and its psychological and educational correlates: A construct validity approach. Psychology in the Schools, 43(3), 267-281. http://dx.doi.org/10.1002/pits.20149 
Martin, A. J., \& Marsh, H. W. (2008). Academic buoyancy: Towards an understanding of students' everyday academic resilience. Journal of School Psychology, 46, 53-83. http://dx.doi.org/10.1016/j.jsp.2007.01.002

Marton, F., \& Säljö, R. (1976). On qualitative differences in learning - I: Outcome and process. British Journal of Educational Psychology, 46, 4-11. http://dx.doi.org/10.1111/j.2044-8279.1976.tb02980.x

Matsui, T., Matsui, K., \& Ohnishi, R. (1990). Mechanisms underlying math self-efficacy learning of college students. Journal of Vocational Behavior, 37, 225-238. http://dx.doi.org/10.1016/0001-8791(90)90042-Z

McArdle, J. J., \& Nesselroade, J. R. (2003). Growth curve analysis in contemporary psychological research. In J. A. Schinka \& W. F. Velicer (Eds.), Handbook of psychology: Research methods in psychology (pp. 447-480). New York: Wiley.

McInerney, D. M. (2004). A discussion for Future Time Perspective. Educational Psychology Review, 16(2), 141-151. http://dx.doi.org/10.1023/B:EDPR.0000026610.18125.a3

Mehta, P., Sundberg, N. D., Rohila, P. K., \& Tyler, L. E. (1972). Future time perspetives of adolescents in India and the United States. Journal of Cross-Cultural Psychology, 3(3), 293-302. http://dx.doi.org/10.1177/002202217200300307

Moretti, E. (2005). Does education reduce participation in criminal activities? In H. M. Levin (Chair), Symposium on the social costs of inadequate education conducted at Teachers College. New York: Columbia University.

Mugler, F., \& Landbeck, R. (1997). Learning in the South Pacific and phenomenography. Higher Education Research and Development, 16, 227-239. http://dx.doi.org/10.1080/0729436970160209

Nabobo, U. (1998). Cultural values and some implications for classroom learning in the Pacific. Directions, 20(1), 18-22.

Nabobo-Baba, U. (2006). Knowing and learning: An Indigenous Fijian approach. Suva: Institute of Pacific Studies, University of the South Pacific.

Odgers, C. L., Moffitt, T. E., Tach, L. M., Sampson, R. J., Taylor, A., \& Matthews, C. L. (2009). The protective effects of neighborhood collective efficacy on British children growing up in deprivation: A developmental analysis. Developmental Psychology, 45(4), 942-957. http://dx.doi.org/10.1037/a0016162

Okagaki, L. (2001). Triarchic model of minority children's school achievement. Educational Psychologist, 36(1), 9-20. http://dx.doi.org/10.1207/S15326985EP3601_2

Pajares, F. (1996a). Self-Efficacy beliefs and mathematical problem-solving of gifted students. Contemporary Educational Psychology, 21, 325-344. http://dx.doi.org/10.1006/ceps.1996.0025

Pajares, F. (1996b). Self-efficacy beliefs in academic settings. Review of Educational Research, 66(4), 543-578.

Pajares, F. (2006). Self-efficacy beliefs of adolescents. In F. Pajares, \& T. Urdan (Eds.), Adolscence and education (pp. 339-367). Greenwich, CT: Information Age.

Pajares, F., \& Graham, L. (1999). Self-efficacy, motivation constructs, and mathematics performance of entering middle school students. Contemporary Educational Psychology, 24, 124-139. http://dx.doi.org/10.1006/ceps.1998.0991

Pajares, F., \& Johnson, M. J. (1996). Self-efficacy beliefs and the writing performance of entering high school $\begin{array}{llllll}\text { students. } & \text { Psychology in }\end{array}$ http://dx.doi.org/10.1002/(SICI)1520-6807(199604)33:2<163::AID-PITS10>3.0.CO;2-C

Pajares, F., \& Kranzler, J. (1995). Self-efficacy beliefs and general mental ability in mathematical problem solving. Contemporary Educational Psychology, 20, 426-443. http://dx.doi.org/10.1006/ceps.1995.1029

Pajares, F., \& Miller, D. (1994). Role of self-efficacy and self-concept beliefs in mathematical problem solving: A path analysis. Journal of Educational Psychology, 86, 193-203. http://dx.doi.org/10.1037/0022-0663.86.2.193

Pajares, F., \& Schunk, D. H. (2001). Self-beliefs and school success: Self-efficacy, self-concept, and school achievement. In R. Riding, \& S. Rayner (Eds.), Perception (pp. 239-266). London: Ablex Publishing.

Pajares, F., Johnson, J., J, \& Usher, E. L. (2007). Sources of writing self-efficacy beliefs of elementary, middle, and high school students. Research in the Teaching of English, 42(1), 104-120.

Pajares, F., Miller, M. D., \& Johnson, M. J. (1999). Gender differences in writing self-efficacy beliefs of 
elementary school students. Journal of Educational Psychology, 91(1), 50-61. http://dx.doi.org/10.1037/0022-0663.91.1.50

Phan, H. P. (2008). Teaching and learning in the South Pacific: A Vygotskian classroom? In J. Dorovolomo, C. F. Koya, H. P. Phan, J. Veramu, \& U. Nabobo-Baba (Eds.), Pacific education: Issues and perspectives (pp. 68-87). Suva: University of the South Pacific \& Max Publishing Ltd.

Phan, H. P. (2009a). Amalgamation of future time orientation, epistemological beliefs, achievement goals and study strategies: Empirical evidence established. British Journal of Educational Psychology, 79(Pt 1), 155-173. http://dx.doi.org/10.1348/000709908X306864

Phan, H. P. (2009b). Future time perspective in sociocultural contexts: A discussion paper. Electronic Journal of Research in Educational Psychology, 7(2), 761-778.

Phan, H. P. (2010a). Students' academic performance and various cognitive processes of learning: An integrative framework and empirical analysis. Educational Psychology, 30(3), 297-322. http://dx.doi.org/10.1080/01443410903573297

Phan, H. P. (2010b). A theoretical perspective of learning in the Pacific context: A sociocultural perspective. Electronic Journal of Research in Educational Psychology, 8(1), 411-428.

Phan, H. P. (2012a). Informational sources, self-efficacy, and achievement: A temporally displaced approach. Educational Psychology, 32(6), 699-726. http://dx.doi.org/10.1080/01443410.2012.708320

Phan, H. P. (2012b). Relations between informational sources and self-efficacy: A developmental approach. Educational Psychology, 32(1), 81-105. http://dx.doi.org/10.1080/01443410.2011.625612

Phan, H. P. (2012c). A sociocultural perspective of learning: Developing a new theoretical tenet. Paper presented at the Australian Association for Research in Education, $2^{\text {nd }}-6^{\text {th }}$ December, University of Sydney, Sydney.

Phan, H. P. (2013a). Examination of self-efficacy and hope: A developmental approach using latent growth modeling. The Journal of Educational Research, 106, 93-104. http://dx.doi.org/10.1080/00220671.2012.667008

Phan, H. P. (2013b). Interplay between cognitive and non-cognitive processes: Review, implications, and directions. In L. Zhang, \& J. Chen (Eds.), Predictors, Learning Strategies and Influences of Gender (pp. 1-32). Hauppauge, NY: Science Nova Publishing.

Phan, H. P. (In press-2013). Psychosocial processes that facilitate unity and interdependency: Contemplation for research development. The Journal of Educational and Developmental Psychology, 3(1).

Phan, H. P., \& Deo, B. (2007). The revised learning process questionnaire: A validation of a Western model of students' study approaches to the South Pacific context using confirmatory factor analysis. British Journal of Educational Psychology, 77, 719-739. http://dx.doi.org/10.1348/000709906X158339

Phan, H. P., \& Deo, B. (2008). 'Revisiting' the South Pacific approaches to learning: A confirmatory factor analysis study. Higher Education Research and Development, 27(4), 371-383. http://dx.doi.org/10.1080/07294360802406833

Phan, H. P., Maebuta, J., \& Dorovolomo, J. (2010). The relations between personal epistemology and learning approaches in sociocultural contexts: A theoretical conceptualization - Part II. The International Journal of Learning, 17(5), 465-478.

Pintrich, P. R., Smith, D. A. F., Garcia, T., \& McKeachie, W. J. (1993). Reliability and predictive validity of the motivated strategies for learning questionnaire (MSLQ). Educational and Psychological Measurement, 53, 810-814. http://dx.doi.org/10.1177/0013164493053003024

Ravuvu, A. (1983). Vaka I Tauki: The Fijian way of life. Suva, Fiji: Institute of Pacific Studies, The University of the South Pacific.

Ravuvu, A. D. (1988). Development or dependence: The pattern of change in a Fijian village. Suva, Fiji: USP Press.

Rouse, C. E. (2005). The labor market consequences of an inadequate education. In H. M. Levin (Chair), Symposium on the social costs of inadequate education conducted at Teachers College. New York: Columbia University.

Salamonson, Y., Andrew, S., \& Everett, B. (2009). Academic engagement and disengagement as predictors of performance in pathophysiology among nursing students. Contemporary Nurse, 32(1-2), 123-132. 
http://dx.doi.org/10.5172/conu.32.1-2.123

Schön, D. (1983). The reflective practitioner: How professionals think in action. New York: Basic Books.

Schunk, D. H. (1987). Peer models and children's behavioral change. Review of Educational Research, 57, 149-174.

Schunk, D. H. (1995). Self-efficacy and education and instruction. In J. E. Maddux (Ed.), Self-efficacy, adaptation, and adjustment: Theory, research and application (pp. 283-301). New York: Plenum Press. http://dx.doi.org/10.1007/978-1-4419-6868-5_10

Schunk, D. H., \& Hanson, A. R. (1985). Peer models: Influence on children's self-efficacy and achievement. Journal of Educational Psychology, 77, 313-322. http://dx.doi.org/10.1037/0022-0663.77.3.313

Schunk, D. H., \& Hanson, A. R. (1989a). Influence of peer-model attributes on children's beliefs and learning. Journal of Educational Psychology, 81, 431-434. http://dx.doi.org/10.1037/0022-0663.81.3.431

Schunk, D. H., \& Hanson, A. R. (1989b). Self-modeling and children's cognitive skill learning. Journal of Educational Psychology, 81, 155-163. http://dx.doi.org/10.1037/0022-0663.81.2.155

Schunk, D. H., Hanson, A. R., \& Cox, P. D. (1987). Peer-model attributes and children's achievement behaviors. Journal of Educational Psychology, 79(1), 54-61. http://dx.doi.org/10.1037/0022-0663.79.1.54

Schunk, D. H., Pintrich, P. R., \& Meece, J. L. (2008). Motivation in education: Theory, research, and applications (3rd ed.). Upper Saddle River, NJ: Pearson, Merrill, Prentice Hall.

Seijts, G. H. (1998). The importance of future time perspective in theories of work motivation. The Journal of Psychology, 13(2), 154-168. http://dx.doi.org/10.1080/00223989809599156

Sins, P. H. M., van Joolingen, W. R., Savelsbergh, E. R., \& van Hout-Wolters, B. (2008). Motivation and performance within a collaborative computer-based modeling task: Relations between students' achievement goal orientation, self-efficacy, cognitive processing, and achievement. Contemporary Educational Psychology, 33, 58-77. http://dx.doi.org/10.1016/j.cedpsych.2006.12.004

Snyder, C. R., \& Shorey, H. (2002). Hope in the classroom: The role of positive psychology in academic achievement and psychology curriculum. Psychology Teacher Network, 12, 1-9.

Snyder, C. R., Shorey, H. S., Cheavens, J., Pulvers, K. M., Adams, V. H., \& Wiklund, C. (2002). Hope and academic success in college. Journal of Educational Psychology, 94(4), 820-826. http://dx.doi.org/10.1037/0022-0663.94.4.820

Suárez-Orozco, C., Pimentel, A., \& Martin, M. (2009). The significance of relationships: Academic engagement and achievement among newcomer immigrant youth. Teachers College Record, 111(3), 712-749.

Teaero, T. F. (2002). Old challenges, 'new' responses to educational issues in Kiribati. In F. Pene, A. M. Taufe'ulungaki, \& C. Benson (Eds.), Tree of opportunities: Re-thinking Pacific education (pp. 73-83). Suva, Fiji: Institute of Education, USP.

Triandis, H. C., Bontempo, R., Villareal, M. J., Asai, M., \& Lucca, N. (1988). Individualism and collectivism: Cross-cultural perspectives on self-ingroup relationships. Journal of Personality and Social Psychology, 54(2), 323-338. http://dx.doi.org/10.1037/0022-3514.54.2.323

Urdan, T. (2004). Using multiple methods to assess students' perceptions of classroom goal structure. European Psychologist, 9(4), 222-231. http://dx.doi.org/10.1027/1016-9040.9.4.222

Vázquez, S. M., \& Rapetti, M. V. (2006). Future time perspective and motivational categories in Argentinean adolescents. Adolescence, 41, 511-532.

Vygotsky, L. (1978). Mind in society: The development of higher psychological processes. Cambridge, MA: Harvard University Press.

Wertsch, J. V., del Rio, P., \& Alvarez, A. (1995). Sociocultural studies of mind. Cambridge: Cambridge University Press. http://dx.doi.org/10.1017/CBO9781139174299

Woolf, S. H. (2007). Giving everyone the health of the educated: An examination of whether social change would save more lives than medical advances. American Journal of Public Health, 97, 679-683. http://dx.doi.org/10.2105/AJPH.2005.084848 